\title{
Jelly genome mystery
}

\section{Publication of the draft genetic sequence of a combjelly reveals a nervous system like no other.}

\section{BY EWEN CALLAWAY}

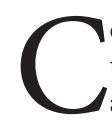

omb jellies, or ctenophores, look like tiny disco balls and propel themselves around oceans using specialized hairs, lapping up small prey with their sticky tentacles. "They are aliens who've come to Earth," says Leonid Moroz, a neuroscientist at the University of Florida in St Augustine.

The genome of the Pacific sea gooseberry (Pleurobrachia bachei), which Moroz and his team report online today in Nature, adds to the mystery of ctenophores (L. L. Moroz et al. Nature http://dx.doi.org/10.1038/nature13400; 2014). The sequence omits whole classes of genes found in all other animals, including genes normally involved in immunity, development and neural function. For that reason, the researchers contend that ctenophores evolved a nervous system independently.

Ctenophores have long vexed taxonomists. Their resemblance to jellyfish earned them a spot on the tree of life as a sister group to cnidarians (the phylum that includes jellyfish). On the basis of their nervous systems which can detect light, sense prey and move musculature - many researchers had them branching off from the common ancestor of all animals after the sponges and flattened multicellular blobs known as placozoans, neither of which have a nervous system. Now armed with data showing that ctenophores lack many common genes, some scientists contend that the jellies represent the earliest lineage to split off from the common ancestor. Moroz's team argues that the $P$. bachei genome, along with gene-expression data from other ctenophores, supports this theory. For example, microRNAs, which regulate gene expression in other animals, are completely missing from the sea gooseberry genome.

The biggest surprise, Moroz says, was the absence of many standard components of a nervous system. Nearly all known nervous systems use the same ten primary neurotransmitters; the Pacific sea gooseberry seems to employ just one or two. Moroz speculates that the organism might complete its nervous system using molecules that researchers have not yet found in this species, such as specialized protein hormones.

The uniqueness of this ctenophore's nervous system leads Moroz and his team to argue that it must have evolved independently, after the ctenophore lineage branched off from other

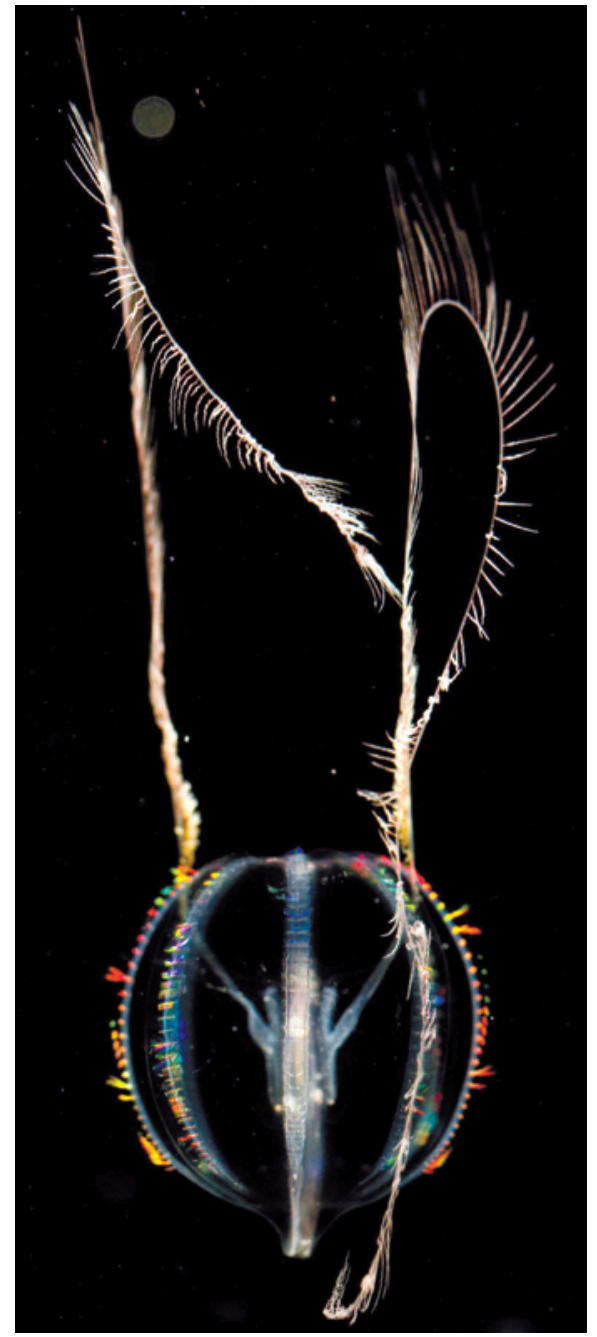

Pleurobrachia bachei lacks many common genes.

animals some 500 million years ago. "Everyone thinks this kind of complexity cannot be done twice," Moroz says. "But this organism suggests that it happens."

Gert Wörheide, an evolutionary geobiologist at Ludwig Maximilian University in Munich, Germany, is intrigued by the theory that the nervous system evolved twice in different animal branches, but disputes that ctenophores were the first lineage to branch off from the common ancestor.

The common ancestor of all animals may have looked nothing like comb jellies, and the $P$. bachei nervous system may be a more recent adaptation, he says. "I think the last word is not spoken yet on where the ctenophores go." 